\title{
OCULAR BIOMETRY IN PRIMARY ANGLE CLOSURE GLAUCOMA
}

\author{
Bheema Divya', Mandapati Vijayaramaraju², Male Yanadi Reddy3 \\ ${ }_{1}^{1}$ Post Graduate, Department of Ophthalmology, SVS Medical College. \\ ${ }^{2} \mathrm{HOD}$, Department of Ophthalmology, SVS Medical College. \\ ${ }^{3}$ Senior Bio-Statistician, SVS Medical College.
}

\section{ABSTRACT}

\section{OBJECTIVE}

To compare the ocular biometric values. Anterior chamber depth, axial length of normal subjects and primary angle closure glaucoma subjects.

\section{MATERIALS AND METHODS}

A prospective case control study of 50 subjects (50 eyes) with equal number of cases and matched controls were studied in a tertiary care centre. Both groups underwent a complete ocular examination with slit lamp biomicroscopy, indentation gonioscopy and ocular biometry using ultrasound ' $\mathrm{A}$ ' scan. Ocular biometric readings between the groups were compared by using unpaired $\mathrm{t}$ test/Mann Whitney 'U' test.

\section{RESULTS}

Mean (SD) age (In years) among normal 50.6 (8.8) and angle closure glaucoma subjects 54.4 (8.3) is not statistically significant. Mean (SD) anterior chamber depth is shallow in PACG 2.34 (0.21) compared to normal subjects 3.03 (0.37) and Mean (SD) axial length is shorter in PACG 21.50 (0.92) compared to normal subjects $22.51(0.84),(\mathrm{P}<0.0001)$ which is statistically significant.

\section{CONCLUSIONS}

The study shows that eyes with angle closure glaucoma have shorter axial length and shallower anterior chamber depth compared to normal eyes.

\section{KEYWORDS}

Primary Angle Closure Glaucoma, Anterior Chamber Depth, Axial Length.

HOW TO CITE THIS ARTICLE: Divya B, Vijayaramaraju M, Reddy MY. Ocular biometry in primary angle closure glaucoma. J. Evolution Med. Dent. Sci. 2016;5(29):1475-1478, DOI: 10.14260/jemds/2016/347

\section{INTRODUCTION}

Glaucoma is considered as the leading cause of irreversible blindness worldwide with Asians accounting for approximately half of the world's glaucoma cases.[1] It has also been accepted that Primary Angle Closure Glaucoma (PACG) is higher in Asians than Europeans and Africans, with over $80.0 \%$ of those with PACG in Asia.[1],[2] In 2013, the number of people (Aged 40-80 years) with glaucoma worldwide was estimated to be 64.3 million, increasing to 76.0 million in 2020 and 111.8 million in 2040.[3]

A meta-analysis conducted by Cheng JW et al. showed the overall pooled prevalence of PACG in those of adult Asians was $0.75 \%$, ethnicity-specific pooled prevalence estimates were $0.46 \%$ in India group and showed age-specific prevalence was more among age groups 60-69 and above 70 . The overall female-to-male ratio of the PACG prevalence was 1.51:1.[4] It is estimated that PACG blinds two to five times more individuals than primary open angle glaucoma.[5]

Clinical based studies have suggested that eyes with PACG have a shorter axial length and shallow anterior chamber.[6-9]

Financial or Other, Competing Interest: None.

Submission 18-02-2016, Peer Review 15-03-2016,

Acceptance 21-03-2016, Published 09-04-2016.

Corresponding Author:

Bheema Divya,

SVS Medical College and Hospital,

Yenugonda,

Mahabubnagar.

E-mail: divyabheema.06@gmail.com

DOI: $10.14260 /$ jemds $/ 2016 / 347$
Rosengren.[10] found that glaucoma patients had a shorter anterior chamber depth than normal subjects and shallow anterior chamber in PACG patients existed prior to rise in pressure. Tornquist.[11] found anterior chamber to be genetically determined. He also reported that anterior chamber of the fellow eye of persons with uniocular glaucoma is shallower compared to normal. Sir Lowe in 1970 stated that the characteristic shallow anterior chamber of PACG is caused by abnormal correlation between structure of lens and eyeball.

The growth of lens leads to shallowing of anterior chamber depth by 0.35 to $0.5 \mathrm{~mm}$ in 50 years. The dimensions of anterior chamber caused by growth of lens may play an important role in the pathogenesis of PACG.

This study is undertaken to show significant association of anterior chamber depth and axial length for the occurrence of the disease in Indian subjects. Early detection by effective screening and appropriate prophylaxis may prevent blindness from angle closure glaucoma.

\section{MATERIAL AND METHODS}

The study comprised of patients of age group 35-70 years of both gender attending to the Ophthalmology Outpatient Department of SVS Medical College, Mahabubnagar, Telangana state during January 2015 to December 2015; 50 subjects with equal number of cases and matched controls were listed.

A patient was assigned to the PACG group if his or her eye had an occludable angle and a visual field defect compatible with glaucomatous optic neuropathy. Optic neuropathy was defined as a vertical cup-to-disc ratio (CDR) $\geq 0.7$ or asymmetry $\geq 0.2$ or neuroretinal rim width reduced to $\leq 0.1$ CDR. 
Two consecutive reliable visual field examinations performed to prove significant glaucomatous defect.

\section{Inclusion Criteria}

Proven cases of primary angle closure glaucoma are included.

\section{Exclusion Criteria}

- With plateau iris configuration.

- With previous history of Acute Angle-Closure Glaucoma (AACG).

- Who had received peripheral laser iridotomies or intraocular surgery.

- Eyes with secondary glaucoma mechanisms.

- $\quad$ Those who are taking miotics and other antiglaucoma medications.

Informed consent is taken and all subjects underwent visual activity measurement, slit lamp examination, Goldmann applanation tonometry, indentation gonioscopy and stereo biomicroscopic examination of the optic disc using a $78 \mathrm{D}$ lens. Gonioscopy is performed with a Sussman indentation gonioscopy in dim illumination using a shortened slit beam that did not fall up on the pupil. The modified Shaffer grading system was used and angle grade and degree of pigmentation recorded in clock hours.

Angles are indented open to look for synechiae and extent of closure in eyes where angle structures were not visualised. Cases with raised IOP or glaucomatous optic disc changes are advised to have visual field testing on the Humphrey field analyser. Biometry is performed after anterior segment examination and gonioscopy. The ocular surface is anaesthetised with $0.5 \%$ oxybuprocaine hydrochloride eye drops and biometry is performed using Alcon ultrasonic biometer. The axial length and anterior chamber depth were measured for all eyes before the use of any mydriatics or pilocarpine.

\section{STATISTICAL ANALYSIS}

The patient characteristics and biometric data of two groups are first summarized descriptively as Mean (SD). The comparison between two groups for continuous normal data and continuous non-normal data is analysed by using unpaired t-test/Mann Whitney ' $U$ ' test. All ' $P$ ' values $<0.05$ were considered as statistically significant.

\section{RESULTS}

The study comprised of total 50 patients (50 eyes) with equal number of cases and controls of age groups $30-70$ years being evaluated. The mean age among normal individuals 50.6 years does not have any significant difference $(\mathrm{P}=0.115)$ in mean age of angle closure glaucoma subjects 54.4 years as shown in Table 1.

\begin{tabular}{|c|c|c|c|c|c|}
\hline Parameter & Group & N & Range & $\begin{array}{c}\text { Mean } \\
\text { (SD) }\end{array}$ & $\begin{array}{c}\text { P- } \\
\text { Value }\end{array}$ \\
\hline $\begin{array}{c}\text { Age } \\
\text { (In years) }\end{array}$ & Control & 25 & 35 to 70 & $50.6(8.8)$ & \multirow{2}{*}{0.115} \\
\cline { 2 - 5 } & Glaucoma & 25 & 35 to 70 & $54.4(8.4)$ & \\
\hline Table 1: The Age (In years) Comparison between Control \\
and Glaucoma Groups
\end{tabular}

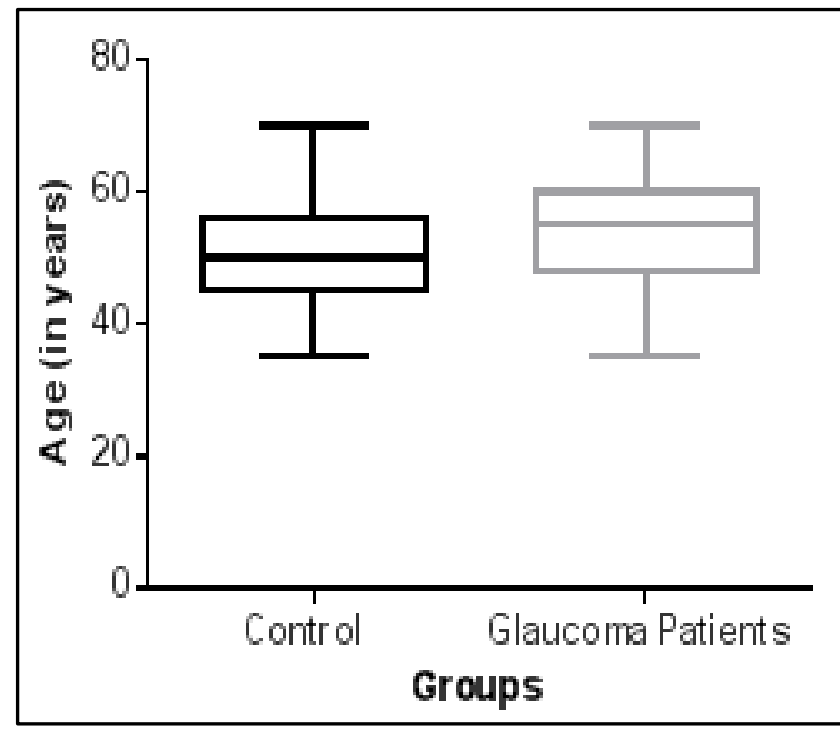

Fig. 1: Box Plot for the Age (In years) Comparison between Control and Glaucoma Groups

\begin{tabular}{|c|c|c|c|c|c|}
\hline Parameter & Group & N & Male & Female & $\begin{array}{c}\text { P- } \\
\text { Value }\end{array}$ \\
\hline \multirow{2}{*}{ Sex } & Control & 25 & 12 & 13 & \multirow{2}{*}{1.000} \\
\cline { 2 - 5 } & Glaucoma & 25 & 11 & 14 & \\
\hline \multicolumn{6}{|c|}{ Table 2: Gender (Male/Female) Comparison between } \\
Control and Glaucoma Groups
\end{tabular}

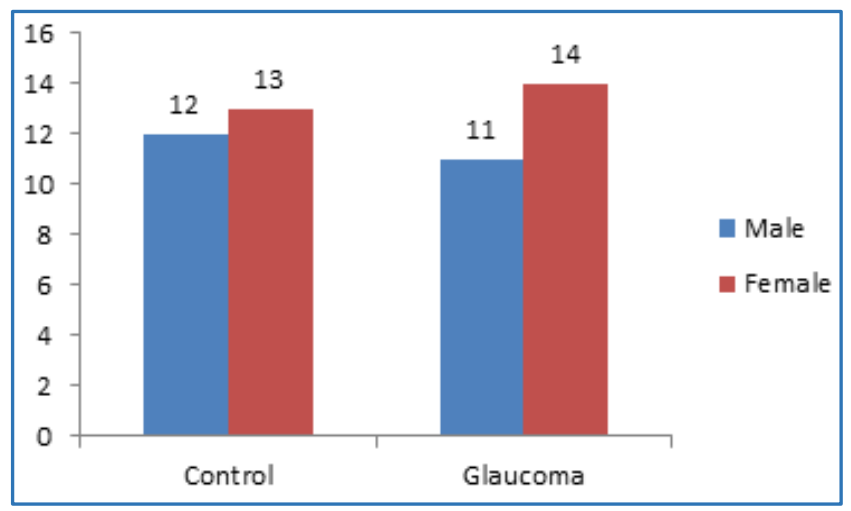

Fig. 2: Cluster Bar Diagram for the Gender (Male/Female) Comparison between Control and Glaucoma Groups

Ocular biometric values were significantly different between the two groups shown in Table 3 and 4. Mean anterior chamber depth was significantly shallow in primary angle closure glaucoma subjects 2.34 (0.21) than normal group 3.03 (0.37), $\mathrm{P}<0.0001$. Group with primary angle closure glaucoma had significantly $\mathrm{P}<0.0001$ shorter axial length $21.05(0.92)$ than normal subjects $22.51(0.84) \mathrm{mm}$.

\begin{tabular}{|c|c|c|c|c|c|}
\hline Parameter & Group & N & Range & $\begin{array}{c}\text { Mean } \\
\text { (SD) }\end{array}$ & $\begin{array}{c}\text { P- } \\
\text { Value }\end{array}$ \\
\hline \multirow{2}{*}{ ACD } & Control & 25 & $\begin{array}{c}2.35 \text { to } \\
3.69\end{array}$ & $\begin{array}{c}3.03 \\
(0.37)\end{array}$ & $<$ \\
\cline { 2 - 5 } (In $\mathrm{mm})$ & Glaucoma & 25 & $\begin{array}{c}2.02 \text { to } \\
2.84\end{array}$ & $\begin{array}{c}2.34 \\
(0.21)\end{array}$ & 0.0001 \\
\hline
\end{tabular}

Table 3: The ACD (In mm) Comparison between Control and Glaucoma Groups 


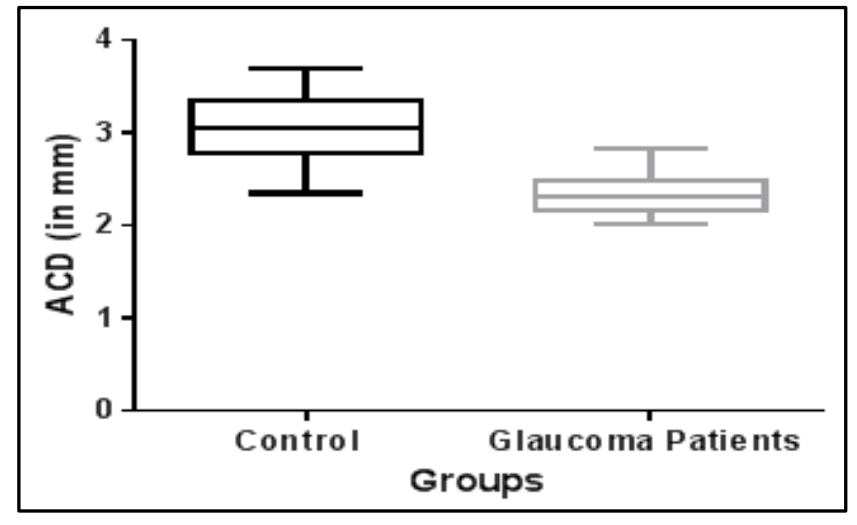

Fig. 3: Box Plot for the ACD (In mm) Comparison between Control and Glaucoma Groups

\begin{tabular}{|c|c|c|c|c|c|}
\hline Parameter & Group & N & Range & $\begin{array}{c}\text { Mean } \\
\text { (SD) }\end{array}$ & $\begin{array}{c}\text { P- } \\
\text { Value }\end{array}$ \\
\hline \multirow{3}{*}{ AXL } & Control & 25 & $\begin{array}{c}20.41 \text { to } \\
23.61\end{array}$ & $\begin{array}{c}22.51 \\
(0.84)\end{array}$ & \multirow{2}{*}{$<0.0001$} \\
\cline { 2 - 5 } (In mm) & Glaucoma & 25 & $\begin{array}{c}20.02 \text { to } \\
23.32\end{array}$ & $\begin{array}{c}21.50 \\
(0.92)\end{array}$ & \\
\hline \multicolumn{7}{|c|}{ Table 4: The AXL (In mm) Comparison between Control } \\
and Glaucoma Groups
\end{tabular}

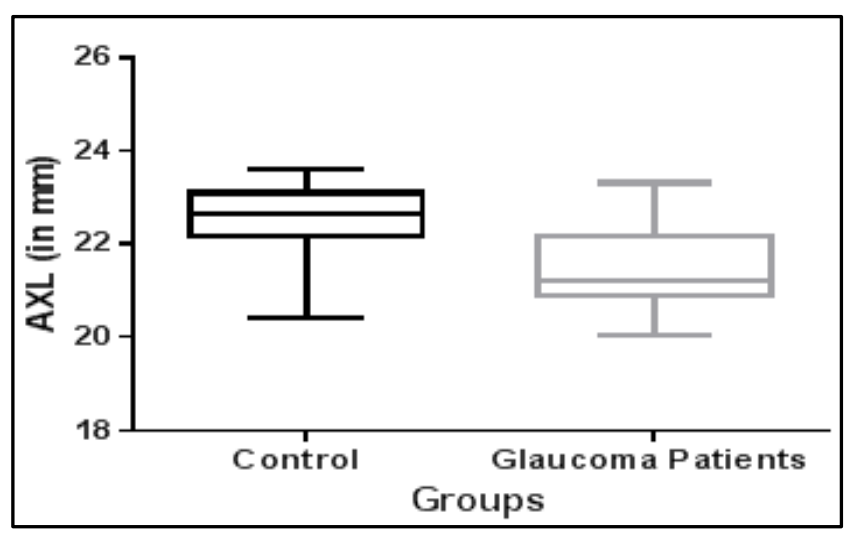

Fig. 4: Box Plot for the AXL (In mm) Comparison between Control and Glaucoma Groups

\section{DISCUSSION}

PACG is a common form of glaucoma in Asians, Eskimos and Inuits.[12] Previous studies have compared the ocular biometry of people with and without PACG eye.[9] and found eyes with PACG have ocular features, which predisposed them to develop the disease. Literature shows that eyes with angle closure glaucoma have shorter axial length; shallower anterior chamber depth.

Angle closure glaucoma is more prevalent in Asia.[3] It is known that women are more susceptible to angle closure glaucoma than men. ${ }^{[4]}$ In the present study patients, we found significantly larger proportion of women in the group with angle closure glaucoma than the normal subjects.

Similar findings were reported in a systematic review and meta-analysis by J.W. Cheng et al. ${ }^{[4]}$ which showed the rate of PACG prevalence increased with age, approximately double per decade. PACG prevalence in women was approximately 1.5 times than in men.

The Bhaktapur glaucoma study by Thapa SS.[13] shows the eyes in Nepalese population with occludable and angleclosure to have significantly shallower anterior chambers and shorter axial lengths when compared with the normal group. A similar population based study by R George et al. concluded eyes with angle closure glaucoma; occludable angles have significantly shorter axial lengths and shallower anterior chamber on comparison to normal group. These findings are consistent with our present study. Our study shows significantly shorter axial length in PACG group, which was consistent with other studies.

A study conducted in by Sherpa D, Badhu BP.[14] showed that patients with axial length of less than $23 \mathrm{~mm}$ are at risk to develop primary angle closure glaucoma. Lowe.[15] and Alsbirk.[16] reported that PACG was uncommon in eyes with central ACD $>2.5 \mathrm{~mm}$. It has been suggested that measurement of ACD can be applied for screening angle closure glaucoma. ${ }^{[17]}$

In the present study an unpaired t-test was done to compare mean anterior chamber depth, axial length between groups shows statistically significant $\mathrm{P}<0.0001$. These results can be confirmed by doing population based study in a large sample size.

\section{SUMMARY}

In the present study 50 patients ( 50 eyes) with equal number of cases and controls are evaluated with detailed history, ocular examination and biometric data was taken from both the groups using A-scan ultrasonography.

The results of present study show that the ocular biometric variables like shallow axial length, shallow anterior chamber depth in primary angle closure glaucoma group may predict risk of developing the disease with statistical significance $(\mathrm{P}<0.0001)$ and $\mathrm{A}$-Scan ultrasonography can be used for screening and early detection of primary angle closure glaucoma.

\section{REFERENCES}

1. Quigley HA, Broman AT. The number of people with glaucoma worldwide in 2010 and 2020. Br J Ophthalmol 2006;90(3):262-7.

2. Wong TY, Loon SC, Saw SM. The epidemiology of age related eye diseases in Asia. $\mathrm{Br} \mathrm{J}$ Ophthalmol 2006;90(4):506-11.

3. Tham YC, Li X, Wong TY, et al. Global prevalence of glaucoma and projections of glaucoma burden through 2040: a systematic review and meta-analysis. Ophthalmology 2014;121(11):2081-90.

4. Cheng J, Zong Y, Zeng Y, et al. The prevalence of primary angle closure glaucoma in adult asians: a systematic review and meta-analysis. Plos One 2014;9(7):e103222.

5. Foster PJ, Oen FT, Machin D, et al. The prevalence of glaucoma in Chinese residents of Singapore: a crosssectional population survey of the tanjongpagar district. Arch Ophthalmol 2000;118(8):1105-11.

6. Sihota R, Gupta V, Agarwal HC, et al. Comparison of symptomatic and asymptomatic, chronic, primary angleclosure glaucoma, open-angle glaucoma, and controls. J Glaucoma 2000;9(3):208-13.

7. Panek WC, Christensen RE, Lee DA, et al. Biometric variables in patients with occludableanterior chamber angles. Am J Ophthalmol 1990;110(2):185-8.

8. Tomlinson A, Leighton DA. Ocular dimensionsn the heredity of angle closure glaucoma. Br J Ophthalmol 1973;57(7):475-86. 
9. George R, Paul PG, Baskaran M, et al. Ocular biometry in occludable angles andangle closure glaucoma: a population basedsurvey. $\mathrm{Br} \mathrm{J}$ Ophthalmol 2003;87(4):399-402.

10. Shaffer RN. Symposium: primary glaucomas. III. Gonioscopy, ophthalmoscopy and perimetry. Trans Am Acad Ophthalmol Otol 1960;62:112.

11. Törnquist R. Shallow anterior chamber in acute angleclosure. A clinical and genetic study. Acta Ophthalmol 1953;31(39):1-74.

12. Sood NN, Jain RC, Agarwal HC. Ocular biometry in primary angle closure glaucoma in Indians. Indian J Med Res 1988;88:190-1.

13. Thapa SS, Paudyal I, Khanal S, et al. Comparison of axial lengths in occludable angle and angle-closure glaucomathe bhaktapur glaucoma study. Optom Vis Sci 2011;88(1):150-4.
14. Sherpa D, Badhu BP. Association between axial length of the eye and primary angle closure glaucoma. Kathmandu university Med J 2008;6(23):361-3.

15. Lowe RF. Primary angle-closure glaucoma. Inheritance and environment. Br J Ophthalmol 1972;56(1):13-20.

16. Alsbirk PH. Anterior chamber depth and primary angleclosure glaucoma. I. An epidemiologic study in Greenland Eskimos. Acta Ophthalmol (Copenh) 1975;53(1):89104.

17. Nolan WP, Baasanhu J, Undraa A, et al. Screening for primary angle closure in Mongolia: a randomised controlled trial to determine whether screening and prophylactic treatment will reduce the incidence of primary angle closure glaucoma in an east Asian population. Br J Ophthalmol 2003;87:271-4. 